\title{
Validity of Communication Skills Attitude Scale among Malaysian Medical Students
}

\author{
Md. Anayet Ullah ${ }^{1}$, Arunodaya Barman ${ }^{1}$, Ahmad Fuad Abdul Rahim ${ }^{1}$, \\ Muhamad Saiful Bahri Yusoff ${ }^{1}$
}

\begin{abstract}
The Communication skills Attitudes Scale (CSAS) developed by Ress, et al. (2002) has been a widely used instrument for measuring communication skills. With the view to check the validity and reliability of CSAS, a pilot study was carried out to assess the attitudes of undergraduate medical students of Universiti Sains Malaysia (USM) towards communication skills for teaching-learning and its determinants. Thirty five undergraduate USM students were selected from the $1 \mathrm{st}$, 3rd and 5 th years by 3 steps stratified random sampling. Data were collected from the students by a self-administered questionnaire. Factor analysis was conducted to assess construct validity and Cronbach's alphas were calculated to evaluate internal consistency. Principal component analysis (PCA) of the scores from 26 items in the instrument showed 8 factors. Three items were less than 0.4 on any of the two factors in the two factor model. Factor 1 comprised of 15 items including 11 positive items that were positive and 4 negative items $(>0.4)$ with a overall weak load $(<0.4)$ on factor 2 While, factor 2 had 8 items including 7 negative items that were positive and 1 positive item that was negative $(>0.4)$ with an overall weak load $(<0.4)$ on factor 1 . The internal consistency of positive attitudes scale (PAS) and negative attitudes scale (NAS) were $\alpha=0.875$ and $\alpha=0.748$ respectively. The CSAS was found to be valid and reliable to measure the positive and negative attitudes of the USM undergraduate medical students towards communication skills with modest modifications.
\end{abstract}

Keywords: validity, undergraduate medical students, communication skills, attitudes, Malaysia

\section{Background}

By the late nineties, most of the medical schools of the world incorporated communication skills training in their curriculum (Frederikson \& Bull, 1992). Medical schools in Malaysia have also been incorporating communication skills training into the undergraduate medical curriculum for the last 10 years. Universiti Sains Malaysia (USM) has introduced it in its undergraduate medical curriculum in 2000 (Azila et al., 2006). Medical students' attitudes toward communication skills training have long been a great concern among medical teachers, curriculum planners and policy makers.

\footnotetext{
${ }^{1}$ Department of Medical Education, School of medical sciences, Universiti Sains Malaysia 16150 Kubang Kerian, Kelantan,Malaysia

Corresponding author:

Dr. Md. Anayet Ullah

Department of Medical Education,

School of medical sciences, Universiti Sains Malaysia 16150 Kubang Kerian, Kelantan, Malaysia.

Tel: +609 7664877 (Office), H/P: +6 0169619004

Fax: +6097653370
}

Email: md.anayet_u@yahoo.com
Although it has been a decade since communication skills are an integral part of the medical school curricula in Malaysia, literature about student's attitude in this area are still lacking. In order to explore the impact and to strengthen the training program, there is no method for assessment of student's attitude towards communication skills currently in use. This pilot study was undertaken to verify the validity and reliability of CSAS originally developed by Rees et al. (2002) to assess the attitudes regarding communication skills among undergraduate USM medical students.

\section{Methodology}

Thirty five undergraduate medical students were selected from the $1^{\text {st }}, 3^{\text {rd }}$ and $5^{\text {th }}$ years. Approximately equal proportions in number i.e. 12 from $1^{\text {st }}, 12$ from $3^{\text {rd }}$ and 11 from $5^{\text {th }}$ year students were selected using a stratified random sampling technique. The proportion of ethnic groups (Malay, Chinese and Indian) and gender of students were 1:1:1 and $1: 1$ respectively. Stratification was done twice to select students in each year. Data were collected from students through a selfadministered questionnaire using CSAS. 
Factor analysis using a principal component analysis (PCA) was conducted from the collected data of 26 items to determine the factors underpinning the scale. Two factors were extracted with positive attitudes scale (PAS) and negative attitudes scale (NAS). The items that were more than 0.4 on any of the two factors and at least 0.10 lower were included in the scale. Item based internal consistency reliabilities for positive attitude and negative attitude subscales of CSAS were assessed using Cronbach's alpha after reversing the scores of the negatively loaded items of respective subscales. On the basis of the factor loading analysis and Cronbach's alpha test, the CSAS was modified

\section{Results}

Kaiser-Meyer-Olkin measure of sampling adequacy was 0.504 and Bartlett's test of sphericity showed a significance of $<0.001$.

Out of 26 items, 3 items failed to load more than 0.4 on any of the two factors. Of the 3 items, (item 23) was positive and (items 13 and 20) were negative statements. Of the remaining 23 items, 15 were $(>0.4)$ on factor 1 and 8 on factor 11 . Out of the 15 items comprising factor 1 - 11 (item 1, 4, 5, 7, 9, 10, $12,14,16,18$ and 21) were positive statements loaded positively and the remainder (item 2 , $15,19,26)$ were negative statements loaded negatively. Of the 8 items comprising factor 2 , 7 (item $3,6,8,11,17,22,24$ ) were negative statements loaded positively and 1 item (23) was a positive statement loaded negatively (Table 1).

After reversing the scores for 4 negative items $(2,15,19,26)$ loaded negatively to factor 1 and 1 positive item (23) loaded negatively to factor 2, the internal consistency of the 15 items of factor I was $\alpha=0.875$ and 8 items of factor II was $\alpha=0.748$ respectively.

\section{Discussion}

According to Raubenheimer's (2004) recommendation, this study suggested exclusion of 3 items, 1 positive item (25) and 2 negative items (13 and 20$)$ from the scale in the two factors model. They were loaded weakly $(<0.4)$ on both factors. Although during development of the CSAS Rees et al. (2002) included all items in the scale irrespective of their loading values, item 13 and 20 loaded weakly ( 0.367 and 0.227 respectively) on both the subscales in their study. Initially Rees et al. (2002) put item 1 and item 22 under PAS and NAS respectively but later they moved item 1 to NAS and item 22 to PAS due to negative loading of item 1 on NAS and item 22 on PAS. In the present study, both items were loaded satisfactorily $(>0.04)$ on their initial subscales with weakly loading $(<0.04)$ on the opposite subscales. It is consistent with the findings of Harlak et al. (2008) in Turky. The positive items $4,5,7,9,10,12,14,16,18$ and 21 were satisfactorily loaded on factor I (represented PAS) and were weakly loaded on factor II (represented NAS) similar to findings of Rees et al. (2002).

The remaining positive item (23) satisfactorily loaded negatively on factor 2 . In the study of Harlak et al. (2008), negative items were 2, 19, and 26 and they were negatively loaded on factor I, which were supposed by to be loaded on factor II according to Rees et al. (2002). Similar findings were also seen in this study and the additionally negative item 15 was satisfactorily loaded negatively on Factor II. Further the negative items $3,6,8,11,17$ and 24 satisfactorily loaded on factor 2 (represented NAS) and weakly loaded on factor I (represented PAS) in this study similar to the findings of Rees et al. (2002).

The findings of our study suggest inclusion of all positive items of CSAS under PAS score except item 25 (excluded from the scale) and item 23 (negatively loaded on factor II). Additionally 4 negative items (2, 15, 19 and 26) with reverse score due to negatively loaded on factor I. This study also suggests to include all negative items of CSAS under NAS score except items 13 and 20 (excluded from the scale), and items 2, 15, 19 and 26 (negatively loaded on factor I). Additionally positive item 23 had a reverse score due to negatively loading on factor II.

Internal consistency analysis of this study indicates that the two subscales of the CSAS are reliable with PAS being more reliable than NAS. It is consistent with the previous study findings (Rees et al, 2002; Harlak et al., 2008).

Small sample size was one of the limitations of this pilot study. The critical value (marginally $>$ 0.5 ) of Kaiser-Meyer-Olkin measure of sampling adequacy also suggested the necessity of greater sample size for factor analysis in this study. However, further study is needed with a larger group of students in this area.

Finally, the present study suggests that CSAS is a valid and reliable instrument to measure Malaysian undergraduate medical students' attitude towards communication skills with modest modification of the subscales.

This study also recommends that CSAS could be used to measure the undergraduate medical students' attitudes in different countries other than UK after adjustment. 
Table 1 Rotted pattern matrix with loading for each item of the two factors

\begin{tabular}{|c|c|c|}
\hline Item & Factor I & Factor II \\
\hline 1. In order to be a good doctor I must have good communication skills & 0.422 & -0.197 \\
\hline 2. I can't see the point in learning communication skills & -0.575 & 0.109 \\
\hline $\begin{array}{l}\text { 3. Nobody is going to fail their medical degree for having poor } \\
\text { communication skills }\end{array}$ & 0.187 & 0.434 \\
\hline $\begin{array}{l}\text { 4. Developing my communication skills is just as important as } \\
\text { developing my knowledge of medicine. }\end{array}$ & 0.646 & 0.189 \\
\hline $\begin{array}{l}\text { 5. Learning communication skills has helped or will help me respect } \\
\text { patients. }\end{array}$ & 0.788 & 0.148 \\
\hline 6. I haven't got time to learn communication skills & -0.026 & 0.643 \\
\hline 7. Learning communication skills is interesting & 0.687 & -0.219 \\
\hline 8. I can't be bothered to turn up to sessions on communication skills & -0.210 & 0.520 \\
\hline $\begin{array}{l}\text { 9. Learning communication skills has helped or will help facilitate my } \\
\text { team working skills. }\end{array}$ & 0.690 & 0.243 \\
\hline $\begin{array}{l}\text { 10. Learning communication skills has or will improve my ability to } \\
\text { communicate with patients. }\end{array}$ & 0.809 & 0.035 \\
\hline $\begin{array}{l}\text { 11. Communication skills teaching states the obvious and then } \\
\text { complicates it. }\end{array}$ & 0.046 & 0.764 \\
\hline 12. Learning communication skills is fun. & 0.451 & -0.274 \\
\hline 13. Learning communication skills is too easy ${ }^{a}$ & -0.017 & 0.124 \\
\hline $\begin{array}{l}\text { 14. Learning communication skills has helped or will help me respect } \\
\text { my colleagues }\end{array}$ & 0.793 & 0.163 \\
\hline $\begin{array}{l}\text { 15. I find it difficult to trust information about communication skills } \\
\text { given to me by non-clinical lecturers. }\end{array}$ & -0.403 & 0.149 \\
\hline $\begin{array}{l}\text { 16. Learning communication skills has helped or will help me } \\
\text { recognize patients' rights regarding confidentiality and informed } \\
\text { consent. }\end{array}$ & 0.471 & 0.134 \\
\hline $\begin{array}{l}\text { 17. Communication skills teaching would have a better image if it } \\
\text { sounded more like a science subject. }\end{array}$ & 0.394 & 0.504 \\
\hline $\begin{array}{l}\text { 18. When applying for medicine, I thought it was a really good idea to } \\
\text { learn communication skills. }\end{array}$ & 0.679 & -0.196 \\
\hline 19. I don't need good communication skills to be a doctor & -0.445 & 0.092 \\
\hline $\begin{array}{l}\text { 20. I find it hard to admit to having some problems with my } \\
\text { communication skills }{ }^{a}\end{array}$ & -0.351 & -0.24 \\
\hline $\begin{array}{l}\text { 21. I think it's really useful learning communication skills on the } \\
\text { medical degree. }\end{array}$ & 0.658 & -0.101 \\
\hline $\begin{array}{l}\text { 22. My ability to pass exams will get me through medical school rather } \\
\text { than my ability to communicate }\end{array}$ & -0.320 & 0.436 \\
\hline 23. Learning communication skills is applicable to learning medicine. & 0.374 & -0.465 \\
\hline 24. I find it difficult to take communication skills learning seriously. & -0.104 & 0.828 \\
\hline $\begin{array}{l}\text { 25. Learning communication skills is important because my ability to } \\
\text { communicate is a lifelong skill }{ }^{\mathrm{a}} \text {. }\end{array}$ & 0.105 & -0.366 \\
\hline $\begin{array}{l}\text { 26. Communication skills learning should be left to psychology } \\
\text { students, not medical student. }\end{array}$ & -0.563 & 0.134 \\
\hline
\end{tabular}

${ }^{a}$ Excluded from the scale 


\section{Acknowledgement}

We would like to express our gratitude to Universiti Sains Malaysia short term grant authority for sanctioning the grant.

\section{References:}

Azila, N.M.A., Rogayah, J. \& Zabidi-Hussin, Z.A.M.H.Z (2006) Curricular trends in malaysian medical school: innovations within, Ann Acad Med Singapore, 35, pp. 647-654.

Frederikson, L. \& Bull, P. (1992) An appraisal of the current status of communication skill training in British medical schools, Soc Sci Med, 34(5), pp. 512-522.
Harlak, H., Dereboy, C. \& Gemalmaz A. (2008) Validation of a Turkish translation of the communication skills attitudes scale with Turkish medical students, Education for Health, pp. 1-8. available at: http://www. educationforhealth.net/

Raubenheimer, J. E. (2004) An item selection procedure to maximize scale reliability and validity, South African Journal of Industrial Psychology, 30(4), pp. 59-64.

Rees, C., Sheard, C. \& Davies, S. (2002) The development of a scale to measure medical students' attitudes towards communication skills learning: the communication skills attitudes scale (CSAS), Medical Education, 36, pp.141-147. 